\title{
Graduate Teaching Mode Exploration Based on the Teaching Concept of Flipped Classroom
}

\author{
Yanhui $\mathrm{CHEN}^{1, \text { a }}$ \\ ${ }^{1}$ Graduate School of Jilin Agricultural University, 130118, Changchun, China \\ aemail:yanhuichenc@126.com
}

Keywords: Flipped classroom; Teaching mode; Exploration

\begin{abstract}
Flipped classroom is a kind of brand-new teaching organization form generated under the ever-maturing education informatization background. The paper applies it to the teaching process of graduates, and it introduces the feasibility and significance of introducing flipped classroom teaching mode in the graduates' teaching, and analyzes how to construct the teaching mode. The paper is expected to provide reference for the education mode innovation of graduates.
\end{abstract}

\section{Introduction}

Flipped classroom is a new kind of teaching mode. In traditional teaching mode, information transfer is done by teachers' teaching in the classroom, and knowledge internalization is accomplished through assignment, operation, or practice by the students alone after class. However, flipped classroom inverts this mode; knowledge teaching will no longer occur in class, but be completed with the assistance of information technology before class; and the main process of internalization of knowledge will occur in the classroom, and be completed with the help and under the guidance of the teacher as well as team collaboration between the classmates. In flipped classroom, students are the autonomous learners who take the initiative to internalize knowledge; teachers are the guides of their studies, resource providers and the organizers of the class activities, and teachers are responsible for individual guidance and answering questions. Based on flipped classroom, the teaching mode reform plays a positive role in making highly-efficient use of class time, enhancing the interaction between teachers and students, improving their learning interest, expanding exploration depth, and opening innovative thinking and it is worth reference.

\section{The Feasibility Analysis of Flipped Classroom in the Graduate Teaching}

It can realize the flipping of teaching arrangement. Flipped classroom helps to achieve the flipping of teaching arrangement. The flipping of teaching arrangement is composed of three basic links: question guiding, autonomous learning and classroom discussion. First of all, on the basis of the students' existing management knowledge and experience, the teachers arouse the interest of the students by posing some "hotspot" or simple questions of management. Second, the students make autonomous learning and think deeply by watching the video provided by the teachers. And they need to feed back to the teachers before class. Students need to solve the questions previously posed by the teacher in the process of learning, and mark the places where they don't understand. Finally, teachers collect the questions students don't understand and solve the questions through discussion and interaction with the students in the classroom ${ }^{[1]}$.

It is suitable for the graduate management teaching. Flipped classroom can effectively change the traditional teaching mode. By using the Internet technology, the teachers release the courses and videos needed to be learned in the new media, and the students discuss with the teachers in the classroom after learning. Flipped classroom also helps to improve the students' consciousness of autonomous learning and to cultivate students' spirit of unity and cooperation.

It can effectively improve the openness and visibility of the teaching contents. Taking advantage of new media, flipped classroom can transfer knowledge through the videos. The teachers will make the teaching contents more intuitive and concrete and enable the students to learn in advance by transcribing the teaching contents of management into video ${ }^{[2]}$. Teaching 
video's contents are very rich, and they can be recorded by the teachers themselves, or use other teachers' teaching video or outstanding management classic video resources on the Internet. The teaching contents are open, and the students can review them at any time to make up for deficiency.

It can enrich the teaching evaluation mode. The teaching mode adopting flipped classroom helps to enrich the teaching evaluation mode. For example, the combination of online evaluation and classroom evaluation, or the combination of teacher's evaluation and student's mutual evaluation can be adopted. Teachers give a mark by students' performance in the group discussion or by in-class tests. Teachers can grasp the students' autonomous learning situations with the help of the Internet technology and statistical software. Flipped classroom helps to from a multi-aspect evaluation mode which can know the graduates' true learning situations and helps to improve the teaching validity of the management course ${ }^{[3]}$.

\section{The Significance of Flipped Classroom in the Teaching Mode of Graduates}

It is conducive to cultivate students' autonomous consciousness, cooperation consciousness, and exploration consciousness. The study of graduates must be initiative, independent and self-controlled and explorative. They must first learn to study positively, think independently and solve questions independently; they must have a study plan and arrangement. Then, they must have cooperation consciousness and communication consciousness.

It is conducive to arouse the students' creative spirit. The training goal of graduates is to cultivate a group of talents with innovative spirit, creative consciousness and innovation ability. The "online” autonomous learning of flipped classroom is conducive to give play to students' subjective initiative; "Offline" classroom interaction is discussion and communication based on questions, and it is a kind of study that can inspire each other in a positive group atmosphere, for students can put forward their own understanding in view of their thought, and can pose doubts against the views of others and provide an explanation.

It is conducive for the students to open their minds and make creation. It is conducive to improve the student's ability of expression and communication. The graduates' learning is not just "being buried in old books and materials" and to study assiduously, it also involves scientific research and creation. The "offline" classroom interaction link is the interaction between students and teachers or between students which is based on the questions, and it is also sharing, communication and discussion taking place in a harmonious and pleasant atmosphere. Students should not only learn to listen to others, more importantly, they must learn to express their opinions and to communicate with others ${ }^{[4]}$.

It is conducive to build a democratic classroom atmosphere and build a harmonious and close relationship between the teachers and the students as well as between the students. The "offline" classroom interaction is the kind of interaction which takes place in a democratic and harmonious atmosphere. In the process of interaction, communication between the teachers and the students and between the students enables them to have an opportunity to interact with and to understand each other.

\section{The Basic Construction Idea of Flipped Classroom Teaching Mode}

Building learner-centered classroom teaching mode breaks through the one-way infusion teaching inertia in the past and it is a significant change of teaching concept and teaching method. For teachers, to reach the real flipping will face a series of challenges from teaching organization and teaching art and so on. Though way of teaching is only a kind of form, it often largely determines the effectiveness of teaching. Marx once said: "Narrative methods must be different from the research methods in the form." The presentation of teaching is the narration through teaching, and people should not equate the teaching with research directly. But the teaching process is the transformation from theoretical system, discipline system to the teaching system, and therefore teaching and research cannot be completely opposite. Especially, in view of the teaching form and teaching organization for graduates, the subjectivity of graduates' say shall be emphasized, 
and the flipping of the teaching process must be tried. Emphasis on the learners' central status, of course, does not mean that the status of the teachers in the teaching process is insignificant.

To reconstruct the teaching links and innovate teaching order. Student's participation degree and depth is the intuitive measure of classroom flipping. In the teaching, teachers pay more attention to guiding the students' ability to analyze and solve questions instead of going by the books or repeat "knowledge points" simply ${ }^{[5]}$. Teaching program will change from "teaching-learning-test" to "learning-teaching-practice": that is in the learning of each topic, first of all, under the guidance of teachers, the students learn astronomically and raise questions, and then teachers organize the class discussion and answer questions, and finally, teaching results are formed under the guidance of the teachers. Change of teaching program highlights the students' learning subjectivity, and is of great importance to improve the teaching effect.

In teaching organization, students are divided into several learning groups, which makes students involved in each teaching link and highlights the students' participation. Question-oriented group learning research will mobilize students' learning initiative and motivation effectively. In teaching organization, reasonable grouping and to guide students to carry out the question-based exploring research will encourage students to enter the question situation, and this is a key link in the process of flipped classroom. In every link of teaching, students' autonomous learning is the basis on which teachers will offer proper guidance and complement, and will focus on the question solutions. The students' full participation in the whole process will makes the class flipped in a real sense. In teaching organization, preparation must be conducted ahead, which could encourage and guide students to actively participate in. In teaching evaluation, developmental evaluation emphasizing process and participation must be paid more attention to, and therefore the effective evaluation feedback mechanism is formed to promote the growth of the students' thought ${ }^{[6]}$. Therefore, we need to use classroom teaching art such as "values clarification" and "spiritual midwifery" to explore the ways to achieve effective interaction in teaching and achieve the classroom flipping.

In the aspect of teaching resources and other supporting information system, a good job in development and sharing as well as making full use of various teaching resources must be done. Flipped classroom teaching method is innovative on the concept, and it puts forward higher request to the teachers and students in practice. In the aspect of teaching resources and other supporting information system, integration of the forces to sort and develop them, and supplementing and perfecting according to the teaching are needed. That is, combining with the teaching outline, it needs to develop and form a relatively stable teaching project, and to accumulate and perfect project teaching database ${ }^{[7]}$. In addition, work can be done through the students' participation design to develop various practice teaching ways which are suitable for the characteristics of students, to fuse and absorb micro course, massive open online course, inquiry learning and other teaching methods, to conduct teaching practice, to make use of modern technological means to carry out the simulation practice and to build a diverse three-dimension simulation practice teaching platform including in-class practice and extracurricular practice, simulation practice and field practice.

\section{Conclusion}

In short, the success or failure of the graduate teaching reform is directly related to the education quality of graduates. In flipped classroom teaching, the teacher is not only the information provider and imparter of knowledge in the traditional sense, but the guide and instructor in students' question-finding, question-thinking and question-solving. The practice of the research in this paper has proved that flipped classroom teaching mode is effective in the practice of graduate teaching reform, and it is expected that the mode will provide theoretical basis for graduate teaching reform.

\section{References}

[1] Zhao Xinglong. The advancement and limitations of flipped classroom teaching [ J ] . Journal 
of the Chinese Society of Education, 2013(4) : 66-68.

[2] Zhang Hongyan. The analysis of challenges in the domestic localization practice of flipped classroom [J] . Data of Culture and Education, 2013( 14) : 158-164.

[3] Chen Yuan. The theoretical interpretation and practice reflection on "flipped classroom" in the college ideological and political theory course $[\mathrm{J}]$. Leading Journal of Ideological \& Theoretical Education, 2015 (12) : 87 990.

[4] Cui Yanhui. Flipped classroom and its application in college English teaching [J]. China Educational Technology, 2014, (11) : 116-121.

[5] Zhang Jinlei. The research on the mode of flipped classroom teaching mode [ $\mathrm{J}]$. Journal of Distance Education, 2012( 4) : $46-51$.

[6] Zhong Xiaoliu. The teaching design research based on flipped classroom in the informatization environment $[\mathrm{J}]$. Open Education Research, 2013 (1):58- 64.

[7] Ma Xiulin. The empirical study of flipped classroom teaching in commonly-required course of college information technology $[\mathrm{J}]$. Journal of Distance Education, 2013 (1) : 79- 85. 